\title{
Effects of recombinant bovine interleukin-8 (rblL-8) treatment on health, metabolism, and lactation performance in Holstein cattle II: Postpartum uterine health, ketosis, and milk production
}

\author{
M. Zinicola, M. L. S. Bicalho, T. Santin, E. C. Marques, R. S. Bisinotto, and R. C. Bicalho* \\ Department of Population Medicine and Diagnostic Sciences, Cornell University, Ithaca, NY 14853-6401
}

\section{ABSTRACT}

To evaluate the effect of recombinant bovine interleukin-8 (rbIL-8) on uterine health and milk production, 2 separate studies were conducted. For study 1, postpartum Holstein cows $(\mathrm{n}=213)$ were randomly allocated into 1 of 3 intrauterine treatment groups: control (CTR, $250 \mathrm{~mL}$ of saline solution), low dose (L-IL8, $11.25 \mu \mathrm{g}$ of rbIL-8 diluted in $250 \mathrm{~mL}$ of saline solution), and high dose (H-IL8, 1,125 $\mu \mathrm{g}$ of rbIL-8 diluted in 250 $\mathrm{mL}$ of saline solution). Intrauterine delivery of treatments was performed within $12 \mathrm{~h}$ of parturition. Cows were evaluated for retained fetal membranes, puerperal metritis, and clinical endometritis. Blood samples were collected immediately before treatment and 1, 2, and $3 \mathrm{~d}$ in milk for assessment of IL-8, haptoglobin, fatty acids, and $\beta$-hydroxybutyrate concentrations. Treatment with rbIL-8 reduced the incidence of puerperal metritis in multiparous cows $(\mathrm{CTR}=34.3$, L-IL8 $=$ 8.11, and H-IL8 = 6.35\%). Both the L-IL8 and H-IL8 groups produced significantly more milk, fat-corrected milk, and energy-corrected milk yields when compared with placebo-treated controls. A second study was performed to confirm the effect of rbIL- 8 on milk production. In study 2, 164 primiparous cows were randomly allocated into 1 of 4 treatment groups: control (CTR, $250 \mathrm{~mL}$ of saline solution), low dose (L-IL8, $0.14 \mu \mathrm{g}$ of rbIL-8), medium dose (M-IL8, $14 \mu \mathrm{g}$ of rbIL-8), and high dose (H-IL8, 1,400 $\mu \mathrm{g}$ of rbIL-8). Treatments were prepared and administered as described for study 1 . Cows in the L-IL8, M-IL8, and H-IL8 groups produced significantly more milk, fat-corrected milk, and energycorrected milk yields when compared with control cows. In conclusion, treatment with rbIL-8 decreased the incidence of puerperal metritis in multiparous cows. The administration of rbIL-8 was repeatedly associated with a dramatic and long-lasting improvement of lactation performance.

Received January 19, 2019

Accepted May 14, 2019.

*Corresponding author: rcb28@cornell.edu
Key words: interleukin-8, puerperal metritis, metabolism, milk production

\section{INTRODUCTION}

Postpartum uterine diseases such as metritis, endometritis, and retained fetal membranes (RFM) are extremely relevant for animal welfare and economic reasons. Such diseases are often painful and cause discomfort, increase costs with treatments, reduce milk production and reproductive efficiency, and increase the risk of culling (Gilbert et al., 2005; Han and Kim, 2005; Overton and Fetrow, 2008). Metritis and endometritis are commonly associated with mixed bacterial infection of the uterus, including by Escherichia coli, Trueperella pyogenes, and Fusobacterium necrophorum (Bicalho et al., 2012). A physiological factor contributing to the increased susceptibility to uterine disease is the natural immunosuppression experienced by cows during the periparturient period (Drackley, 1999; Hammon et al., 2006; Galvao et al., 2010).

Neutrophils are the main leukocyte involved in the release of fetal membranes as well as in bacterial clearance after uterine infection (Hussain, 1989; Kimura et al., 2002). Neutrophil function begins to decline before parturition, reaches a nadir shortly after parturition, and slowly returns to prepartum levels by about $4 \mathrm{wk}$ postpartum (Kehrli and Goff, 1989; Goff and Horst, 1997). Several factors contribute to this decline in neutrophil function including an increase in blood estradiol and cortisol concentrations around calving and nutrient deficiencies such as vitamins $\mathrm{A}$ and $\mathrm{E}$, calcium, and selenium (Goff and Horst, 1997; Kimura et al., 2002; Hammon et al., 2006). In fact, neutrophils from cows with RFM have decreased migration ability and impaired myeloperoxidase activity (Kimura et al., 2002). On the other hand, cows with greater neutrophil influx to the uterus are less susceptible to bacterial infections and are at a lower risk of developing endometritis (Gilbert et al., 2005).

Interleukin- 8 is a pro-inflammatory cytokine and the main chemoattractant for neutrophils. It is produced 
by smooth muscle, epithelial cells, endothelial cells, and cells of the innate immune system with toll-like receptors (Mitchell et al., 2003). Binding of IL-8 to its receptors CXCR1 and CXCR2 on neutrophil surface induces neutrophil activation, stimulates chemotaxis, and increases phagocytosis and killing ability (Mitchell et al., 2003). Kimura et al. (2002) studied plasma IL-8 concentrations in cows with and without RFM from $15 \mathrm{~d}$ before parturition to $15 \mathrm{~d}$ postparturition and observed that cows that did not develop RFM had greater plasma IL-8 concentrations, both before and after calving. Thus, the presence of an effector molecule such as IL-8 to attract neutrophils into the uterus seems essential for maintenance of uterine health.

Our group has developed a recombinant bovine interleukin-8 (rbIL-8) molecule with the original objective of improving postpartum uterine health (Bicalho et al., 2019). We conducted a series of experiments to evaluate the safety of rbIL- 8 administration and to assess its biological activity in vitro and in vivo. We demonstrated that our rbIL-8 molecule elicited the expected biological responses: strong chemoattractant properties in vitro and in vivo (following intravaginal and intrauterine administrations). More importantly, systemic, intrauterine, and intravaginal administration of rbIL8 did not result in detectable undesirable side effects such as fever, increased respiratory rate, dehydration, or signs of pain and discomfort (Bicalho et al., 2019).

Therefore, our original hypothesis was that intrauterine administration of rbIL- 8 would reduce the incidence of postpartum uterine diseases. The objectives of the first study were to evaluate the effects of 2 different doses of rbIL-8 administered intrauterinely within $12 \mathrm{~h}$ of parturition on incidence of RFM, puerperal metritis, and endometritis. Upon completion of this randomized clinical trial we identified an unexpected association of rbIL-8 with an increase in milk production, FCM, and ECM yields when compared with controls. To validate our initial results and further investigate the effects of rbIL-8 on milk production, we conducted a second study (study 2) to evaluate the hypothesis that a single administration of rbIL- 8 within $12 \mathrm{~h}$ of parturition improves lactation performance in Holstein cows. The objective of study 2 was to validate the association of postpartum intrauterine administration of rbIL-8 with increased milk production.

\section{MATERIALS AND METHODS}

\section{Ethics Statement}

The research protocol was reviewed and approved by the Cornell University Institutional Animal Care and Use Committee (protocol number 2013-0039). The methods were carried out in accordance with approved guidelines.

\section{Farm and Management}

Two studies were conducted in a large commercial dairy farm located in Cayuga County, New York. The farm milked approximately 3,800 Holstein cows thrice daily in a rotary parlor with integrated milk meters that record individual production at every milking (DeLaval, Tumba, Sweden). Cows were housed in naturally ventilated freestall barns with concrete stalls bedded with manure solids. All cows were offered a TMR and feed was pushed up 8 times a day. Diets consisted of approximately $55 \%$ forage and $45 \%$ concentrate on a DM basis. Diets were formulated to meet or exceed the NRC nutrient requirements for lactating Holstein cows weighing $650 \mathrm{~kg}$ and producing $45 \mathrm{~kg}$ of $3.5 \% \mathrm{FCM}$ (NRC, 2001). Cow displaying signs of calving were moved to individual maternity pens for delivery, where trained farm personnel assisted with parturition as needed. After calving, cows were transferred to a postpartum pen where they remained for approximately 40 d. Reproductive management on farms for the first service was a Presynch-Ovsynch protocol in combination with estrus detection (Pursley et al., 1995; Moreira et al., 2001). A Resynch (Fricke et al., 2003) protocol was started in nonpregnant cows $33 \pm 3 \mathrm{~d}$ after previous inseminations. A voluntary waiting period of $50 \mathrm{~d}$ was used. Estrus was detected based only on electronic activity sensors worn around the neck (Alpro, DeLaval).

\section{Study Design, Treatments, and Sample Collection}

Two randomized clinical trials were conducted to evaluate the effect of a single intrauterine administration of rbIL-8 shortly after parturition on uterine health and milk production.

Study 1. In total, 213 cows (primiparous, $\mathrm{n}=104$; multiparous, $n=109$ ) were enrolled in the study from July 2014 to August 2014. Cows were blocked by parity and, within block, randomly allocated into 1 of 3 treatment groups: control (CTR; $\mathrm{n}=67)$, low dose of rbIL8 (L-IL8; $\mathrm{n}=80)$, and high dose of rbIL-8 (H-IL8; $\mathrm{n}$ $=66)$. Cows allocated to L-IL8 and H-IL8 received an intrauterine administration of $250 \mathrm{~mL}$ of saline solution containing 11.25 and $1,125 \mu \mathrm{g}$ of rbIL-8, respectively. Control cows received an intrauterine administration of $250 \mathrm{~mL}$ of saline solution. Recombinant bovine IL-8 was produced and purified according to the methods described previously (Bicalho et al., 2019). Treatments were administered by the research team within $12 \mathrm{~h}$ of parturition. Cows were restrained in headlock stanchions and the perineal area was cleansed with paper 
towels and disinfected with $70 \%$ ethanol. A sterile gilt AI catheter (Livestock Concepts, Hawarden, IA) attached to a $250-\mathrm{mL}$ saline bag was introduced into the cranial vagina. The catheter was manipulated into the uterus, the tip was exposed to the uterine lumen, and the treatment was administered into the uterus. To avoid biases, treatment identification was not listed in the data collection forms or in the on-farm management software. Moreover, researchers were masked while performing assays and data analysis.

Blood samples were collected from 60 cows (20 cows per treatment) on d 0 (before treatment), 1, 2, and 3 relative to calving via coccygeal vein/artery puncture into an evacuated tube without anticoagulant (Becton, Dickinson and Company, Franklin Lakes, NJ). Blood samples were transported to the laboratory on ice and centrifuged at 2,000 $\times \mathrm{g}$ for $15 \mathrm{~min}$ at $4^{\circ} \mathrm{C}$. Serum was harvested and frozen at $-80^{\circ} \mathrm{C}$ until assayed. For each cow, BCS was recorded at enrollment and at 35 DIM by a single investigator using a 5 -point scale with a quarter-point system, as previously described (Edmonson et al., 1989). Rectal temperature (RT) was measured at enrollment and at 3,6, and 9 DIM using a digital thermometer (GLA M750, GLA Agriculture Electronics, San Luis Obispo, CA). Milk yield was recorded at every milking using on-farm milk meters, and monthly averages obtained during the first 6 mo postpartum were used for statistical analyses.

Study 2. A total of 164 primiparous cows were enrolled in the study from October 2015 to December 2015. Cows were randomly allocated into 1 of 4 treatment groups: control (CTR; $\mathrm{n}=41$ ), low dose of rbIL-8 (L-IL8; $\mathrm{n}=41$ ), medium dose of rbIL-8 (M-IL8; $\mathrm{n}=$ 41), and high dose of rbIL-8 (H-IL8; $\mathrm{n}=41$ ). Cows allocated to L-IL8, M-IL8, and H-IL8 received a single intrauterine administration of $250 \mathrm{~mL}$ of saline solution containing $0.14,14$, and $1,400 \mu \mathrm{g}$ of rbIL-8, respectively. Control cows received an intrauterine administration of $250 \mathrm{~mL}$ of saline solution. Treatments were administered within $12 \mathrm{~h}$ of parturition as described in study 1. Body condition score was scored at enrollment and at 35 DIM. Rectal temperature was recorded at enrollment. Milk yield was recorded at every milking using on-farm milk meters and monthly averages obtained during the first 6 mo postpartum were used for statistical analyses.

\section{Analyses of IL-8 and Metabolites in Serum (Study 1)}

Concentrations of IL-8 in serum was determined using a human IL-8 ELISA kit (R\&D Systems Inc., Minneapolis, MN), validated for bovine serum (Shuster et al., 1996). Plasma concentrations of fatty acids (NEFA-C kit, Wako Pure Chemical Industries, Rich- mond, VA) and BHB (Williamson and Mellanby, 1974; Sigma-Aldrich, St. Louis, MO) were determined by colorimetric methods. Haptoglobin concentrations were determined using a colorimetric procedure as previously described (Bicalho et al., 2014), and reported as optical density readings at $450 \mathrm{~nm}$ of wavelength. Endotoxin levels from purified rbIL-8 were measured by a chromogenic assay (Pierce, Chromogenic Endotoxin Quant Kit, Thermo Fisher Scientific, Waltham, MA) following manufacturer instructions. Endotoxin levels were $<5$ endotoxin units $/ \mathrm{mL}$ (data not shown). A total of 3 $\mathrm{mL}$ of purified rbIL- 8 was used for treatments. Thus, cows treated with rbIL- 8 received a solution containing endotoxin levels under the FDA limit of $<5$ endotoxin units/kg.

\section{Disease Definitions}

Retained fetal membranes assessed by trained farm personnel were defined as failure to deliver fetal membranes by $24 \mathrm{~h}$ after calving. Puerperal metritis diagnosis was performed by the researcher and by trained farm personnel. Researcher puerperal metritis was diagnosed based on evaluation of vaginal mucus retrieved using a Metricheck device (Metricheck, SimcroTech, Hamilton, New Zealand). Vaginal discharge was scored using a modified 0 to 5 scale $(0=$ no secretion material retrieved; $1=$ clear mucus; $2=$ clear mucus with flecks of pus; $3=$ mucopurulent discharge containing $<50 \%$ of pus; $4=$ mucopurulent discharge containing $\geq 50 \%$ of pus; $5=$ watery, red-brown, fetid vaginal discharge). Cows with a score $=5$ and with a $\mathrm{RT}>39.5^{\circ} \mathrm{C}$ were considered to have puerperal metritis (Sheldon et al., 2006). Farm diagnosis of puerperal metritis was performed daily by trained farm employees. Cows were flagged for a physical examination when showing signs of dullness and depression or when a milk deviation of more than $4.5 \mathrm{~kg}$ was detected. At the physical examination, cows were considered as having puerperal metritis when a fetid, watery, and red-brown uterine discharge combined with systemic illness was observed. For the purpose of this study, cows diagnosed with puerperal metritis by the research team or by farm employees (or both) were grouped together and considered positive for puerperal metritis. Furthermore, information regarding puerperal metritis diagnosis was not exchanged between the researchers and farm personnel. Clinical ketosis (CK) diagnosis was performed by farm personnel and defined as cows with decreased milk production, low rumen fill, weakness, dullness, depression, and high blood concentration of BHB (>1.9 mmol/L). Diagnosis of clinical endometritis was performed by research personnel at 35 DIM based on evaluation of vaginal mucus using a Metricheck device. Cows with a 
score $\geq 3$ were considered to have clinical endometritis. Hyperketonemia (HYK) was defined as cows with serum $\mathrm{BHB}$ concentrations $\geq 1.2 \mathrm{mmol} / \mathrm{L}$ on $\mathrm{d} 1,2$, or 3 .

\section{Statistical Analysis}

Before the initiation of study 1 , sample size calculation was performed using JMP PRO version 12 (SAS Institute Inc., Cary, NC). We assumed that the difference on puerperal metritis incidence between treatment groups would be of 20 percentage units. Considering a type I error rate of $5 \%$ and a power of $80 \%$, a total of 60 animals per treatment group was considered sufficient. To further investigate the effects of rbIL- 8 on milk production, sample size calculation for study 2 was performed considering a standard deviation of 1.5 $\mathrm{kg} / \mathrm{d}$ for milk yield and assuming a type I error of $5 \%$ and a power of $80 \%$. A total of 30 cows per group were deemed necessary to detect a significant difference of $2 \mathrm{~kg} / \mathrm{d}$ between groups. An additional $\sim 15 \%$ of cows were enrolled in the studies to compensate for cows removed from the herd during the study period beyond the control of the investigators.

Descriptive statistical analyses were performed with JMP PRO using the ANOVA function for continuous data and chi-squared and Fisher's tests for categorical data. Body condition score loss was assessed using the GLIMMIX procedure of SAS. Continuous data collected over time were analyzed using general linear mixed models with the MIXED procedure of SAS. Normality and homoscedasticity of residuals were assessed using residual plots. Initial statistical models included the fixed effects of treatment, parity, dystocia, stillbirth, BCS at calving, days of gestation at calving, RT at calving, sire PTA for milk yield, age in days at calving, time, and the 2-way interaction terms between independent variables. Several covariance structures were tested, and the Akaike information criterion was used to select the best model fit. Variables and their respective interaction terms were retained in the model when $P \leq 0.15$. Significances were considered when $P \leq 0.05$ or a trend if $0.05<P \leq 0.10$. For all models, Tukey's honest significance test for multiple comparisons was used. Data are reported as LSM \pm SEM unless otherwise stated.

Categorical variables were analyzed by logistic regression models using the binary distribution of the GLIMMIX procedure of SAS. Initial models included the fixed effects of treatment, parity, dystocia, stillbirth, BCS at enrollment, RT at enrollment, and the interaction term treatment by parity. Variables and their respective interaction terms were retained in the model when $P \leq$ 0.15. Dunnett's significance test for multiple comparisons was used. To evaluate the effect of all rbIL- 8 treat- ments on the incidence of CK, Fisher's exact test was used. Finally, the effect of treatment on reproduction was analyzed by Cox's proportional hazard using the PHREG procedure in SAS. Control groups were used as reference for comparison. Treatment, parity, twin, stillbirth, dystocia, BCS at enrollment, and the interaction treatment by parity were offered to the model as independent variables, and retained when $P \leq 0.15$.

\section{RESULTS}

\section{Descriptive Data}

Descriptive statistics regarding the number of multiparous and primiparous animals enrolled, BCS at enrollment, RT at enrollment, days carried calf, and the incidence of twins, dystocia, stillbirth, and male calf for studies 1 and 2 are depicted in Table 1.

\section{Incidence of Uterine Diseases, Hyperketonemia, and Clinical Ketosis (Study 1)}

Treatment did not affect the incidence of RFM $(\mathrm{CTR}=4.5, \mathrm{~L}-\mathrm{IL} 8=2.5, \mathrm{H}-\mathrm{IL} 8=4.6 \% ; P=0.78)$. The effect of treatment on puerperal metritis incidence is presented in Table 2. A significant treatment by parity interaction was observed for puerperal metritis $(P=0.02)$. Multiparous cows treated with rbIL- 8 had $(P=0.03)$ lower incidence of puerperal metritis when compared with control cows, and no differences were observed between treatment groups for primiparous cows (Table 2). Figure 1 illustrates the effect of rbIL-8 administration on RT. Treatment did not affect RT during the first $9 \mathrm{~d}$ postpartum (Figure 1). Intrauterine administration of rbIL-8 did not affect the incidence of HYK when compared with controls $(\mathrm{CTR}=30.0$, $\mathrm{L}-\mathrm{IL} 8=15.0, \mathrm{H}-\mathrm{IL} 8=20.0 \% ; P=0.46)$. The incidence of CK was not affected by treatment $(\mathrm{CTR}=6.0, \mathrm{~L}-\mathrm{IL} 8$ $=3.7, \mathrm{H}-\mathrm{IL} 8=0.0 \% ; P=0.15)$.

\section{Concentration of IL-8, Fatty Acids, BHB, and Haptoglobin (Study 1)}

The effect of treatment on serum IL- 8 concentration is presented in Figure 2. Serum levels of IL8 was significantly increased $(P=0.04)$ for H-IL8 cows when compared with CTR cows (Figure 2). However, we detected that both L-IL8 and H-IL8 groups had higher $(P<0.05)$ IL-8 serum concentration at d 3 compared with CTR group (Figure 2).

The effect of treatment on serum fatty acid, BHB, and haptoglobin levels is illustrated on Figure 3A-D. A treatment by parity interaction was observed for fatty acid serum concentrations $(P<0.001)$. Multiple com- 
Table 1. Descriptive data for cows enrolled in studies 1 and $2^{1}$

\begin{tabular}{|c|c|c|c|c|c|c|c|c|c|}
\hline Item & \multicolumn{4}{|c|}{ Study 1} & \multicolumn{5}{|c|}{ Study 2} \\
\hline Median parity & 1.5 & 1.5 & 1.5 & - & - & - & - & - & - \\
\hline No. multiparous & 39 & 35 & 35 & - & - & - & - & - & - \\
\hline Total enrolled animals, no. & 80 & 66 & 67 & - & 41 & 41 & 41 & 41 & - \\
\hline Average BCS at enrollment & 3.41 & 3.40 & 3.36 & 0.42 & 3.59 & 3.59 & 3.67 & 3.62 & 0.60 \\
\hline Dystocia, \% & 3.75 & 1.50 & 3.00 & 0.87 & 4.88 & 9.76 & 4.88 & 4.88 & 0.84 \\
\hline Stillbirth, \% & 6.25 & 3.03 & 4.48 & 0.66 & 4.88 & 12.2 & 7.32 & 4.88 & 0.68 \\
\hline Male calf, $\%$ & 46.0 & 38.0 & 34.0 & 0.31 & 36.6 & 34.1 & 46.3 & 34.1 & 0.62 \\
\hline
\end{tabular}

${ }^{1}$ One-way ANOVA and chi-squared analysis were used for comparing continuous and categorical data, respectively. Study 1 : CTR $=250 \mathrm{~mL}$ of saline solution; L-IL8 $=11.25 \mu \mathrm{g}$ of recombinant bovine interleukin-8 (rbIL-8) diluted in $250 \mathrm{~mL}$ of saline solution; H-IL8 $=1,125 \mu \mathrm{g}$ of rbIL-8 diluted in $250 \mathrm{~mL}$ of saline solution. Study 2: CTR $=250 \mathrm{~mL}$ of saline solution; L-IL8 $=0.14 \mu \mathrm{g}$ of rbIL- 8 diluted in $250 \mathrm{~mL}$ of saline solution; M-IL8 $=14 \mu \mathrm{g}$ of rbIL-8 diluted in $250 \mathrm{~mL}$ of saline solution; H-IL8 = 1,400 $\mu \mathrm{g}$ of rbIL-8 diluted in $250 \mathrm{~mL}$ of saline solution.

${ }^{2}$ For the chi-squared test, we followed the assumption that no cell should have an expected frequency of less than 5 ; when the assumption was not satisfied, Fisher's exact test was used.

${ }^{3} \mathrm{RT}=$ rectal temperature.

parison tests depicted that primiparous cows treated with H-IL8 had lower $(P=0.008)$ concentrations of fatty acids in serum compared with CTR (Figure 3A). Conversely, multiparous cows treated with H-IL8 had higher $(P=0.01)$ serum fatty acid concentrations than CTR cows (Figure $3 \mathrm{~A})$. We also observed that multiparous cows treated with rbIL- 8 had higher $(P \leq 0.05)$ fatty acid levels at $\mathrm{d} 1$ than CTR multiparous cows. Serum concentrations of BHB did not differ $(P=0.18)$ between treatment groups (Figure 3C). Finally, haptoglobin concentrations were not different $(P=0.96)$ between treatment groups (Figure 3D).

\section{BCS and Reproductive Performance}

Study 1. Body condition score loss from calving until $35 \mathrm{~d}$ after parturition is illustrated in Figure 4A. Body condition score loss was not affected $(P=0.30)$ by treatment (Figure 4A). Additionally, treatment did not alter $(P=0.95)$ the hazard of pregnancy during the first 280 DIM (adjusted hazard ratio: L-IL8 $=0.91$, $95 \%$ CI: 0.57 to $1.47 ; \mathrm{H}-\mathrm{IL} 8=0.98,95 \%$ CI: 0.59 to $1.63)$.

Study 2. Body condition score loss from calving until $35 \mathrm{~d}$ after parturition is illustrated in Figure 4B.

Table 2. Effects of different recombinant bovine interleukin-8 (rbIL-8) doses on the incidence of puerperal metritis and endometritis in cows from study $1^{1}$

\begin{tabular}{|c|c|c|c|c|c|}
\hline \multirow[b]{2}{*}{ Group } & \multirow{2}{*}{$\frac{\% \text { Incidence (no./no.) }}{\text { Puerperal metritis }}$} & \multirow{2}{*}{$\begin{array}{c}\text { Odds ratio } \\
(95 \% \text { CI })\end{array}$} & \multicolumn{3}{|c|}{$P$-value } \\
\hline & & & $\operatorname{Trt}^{2}$ & Trt $\times$ parity & $\mathrm{D}^{3}$ \\
\hline Primiparous & & & 0.63 & 0.02 & \\
\hline CTR & $12.5(4 / 32)$ & Referent & & & \\
\hline L-IL8 & $26.8(11 / 41)$ & $2.71(0.59-12.4)$ & & & 0.26 \\
\hline H-IL8 & $32.3(10 / 31)$ & $4.65(0.94-22.8)$ & & & 0.11 \\
\hline \multicolumn{6}{|l|}{ Multiparous } \\
\hline CTR & $34.3(12 / 35)$ & Referent & & & \\
\hline L-IL8 & $8.11(5 / 39)$ & $0.13(0.02-0.70)$ & & & 0.03 \\
\hline \multirow[t]{2}{*}{ H-IL8 } & $6.35(5 / 35)$ & $0.18(0.04-0.91)$ & & & 0.03 \\
\hline & Endometritis & & & & \\
\hline CTR & $15.25(9 / 59)$ & Referent & & & \\
\hline L-IL8 & $12.68(9 / 71)$ & $0.43(0.01-1.89)$ & 0.32 & 0.68 & - \\
\hline H-IL8 & $12.28(7 / 57)$ & $0.33(0.06-1.80)$ & & & \\
\hline
\end{tabular}

${ }^{1}$ Study 1: CTR $=250 \mathrm{~mL}$ of saline solution, $\mathrm{n}=67$; L-IL8 $=11.25 \mu \mathrm{g}$ of rbIL- 8 diluted in $250 \mathrm{~mL}$ of saline solution, $\mathrm{n}=80$; H-IL8 $=1,125 \mu \mathrm{g}$ of rbIL- 8 diluted in $250 \mathrm{~mL}$ of saline solution, $\mathrm{n}=66$.

${ }^{2} \mathrm{Trt}=$ treatment.

${ }^{3} \mathrm{D}=$ different rbIL-8 treatment groups were tested against the control group using Dunnett's procedure. 


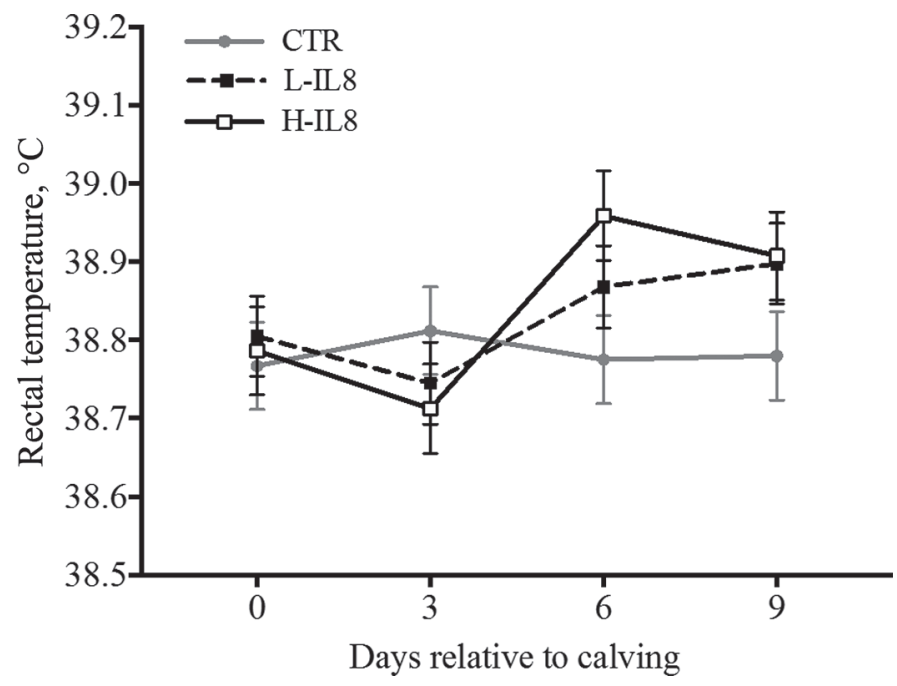

Figure 1. Rectal temperature $\left({ }^{\circ} \mathrm{C}\right)$ of cows treated with different recombinant bovine interleukin-8 (rbIL-8) doses and controls from study 1 . Postpartum cows $(\mathrm{n}=213)$ were randomly allocated into 1 of 3 intrauterine treatment groups: control (CTR; $250 \mathrm{~mL}$ of saline solution), low dose (L-IL8; $11.25 \mu \mathrm{g}$ of rbIL-8 diluted in $250 \mathrm{~mL}$ of saline solution), and high dose (H-IL8, 1,125 $\mu \mathrm{g}$ of rbIL-8 diluted in $250 \mathrm{~mL}$ of saline solution). Results are presented at LSM \pm SEM.

No differences were observed $(P=0.95)$ on BCS loss among treatment groups (Figure 4B).

\section{Lactation Performance}

Study 1. The effects of treatment on milk, FCM, and ECM yields during the first 6 mo after calving are presented on Table 3 and Figure 5A. Treated cows produced approximately $3.3 \mathrm{~kg} / \mathrm{d}$ more $(P<0.05)$ milk compared with controls (Table 3). Relative to CTR, rbIL-8 cows produced approximately $2.7 \mathrm{~kg} / \mathrm{d}$ more FCM $(P=0.004$; Table 3$)$. We observed that cows treated with rbIL- 8 produced approximately 3.0 $\mathrm{kg} / \mathrm{d}$ more ECM compared with CTR cows $(P=0.001$; Table 3).

Study 2. The effect of treatment on milk, FCM, and ECM yields during the first 6 mo after calving are presented in Table 3 and Figure 5B. As observed in study 1, treatment increased milk, FCM, and ECM yields ( $P$ $<0.001)$. We observed that L-IL8, M-IL8, and H-IL8 cows produced $1.2(P=0.06), 2.2(P<0.05)$, and $2.4(P<0.05) \mathrm{kg} / \mathrm{d}$ more milk when compared with controls, respectively (Table 3). Cows in the L-IL8, M-IL8, and H-IL8 groups produced 2.2, 3.0, and 3.4 $\mathrm{kg} / \mathrm{d}$ more $(P<0.05)$ FCM than CTR cows, respectively (Table 3). Moreover, cows in the L-IL8, M-IL8, and H-IL8 groups produced 1.8, 2.8, and $3.2 \mathrm{~kg} / \mathrm{d}$ more $(P<0.05)$ ECM when compared with the CTR group, respectively (Table 3 ).

\section{DISCUSSION}

Herein we demonstrated in 2 independent studies that intrauterine rbIL- 8 administration in the immediate postpartum was associated with a significant increase in milk production. The first study was designed to investigate the effect of intrauterine administration of rbIL-8 on the prevention of postpartum uterine diseases; an unexpected increase in milk production was observed as a result of rbIL- 8 treatment. To further validate the effect of rbIL- 8 administration on milk production, a second study was conducted. In study 1 , the administration of rbIL- 8 reduced the incidence of puerperal metritis in multiparous cows. Moreover, cows treated with intrauterine rbIL-8 at calving produced approximately $3.3,2.7$, and $3.0 \mathrm{~kg} / \mathrm{d}$ more milk, FCM, and ECM yields, respectively, compared with CTR cows during the first 6 mo after parturition. The observed effect of rbIL-8 on milk yield in study 1 was replicated in study 2 , where rbIL- 8 cows produced significantly more milk, FCM, and ECM yields when compared with CTR cows. This is the first scientific manuscript that has demonstrated that milk production can be enhanced with the use of rbIL- 8 .

Interleukin- 8 is a chemokine that binds to $\mathrm{G}$ proteincoupled receptors (CXCR1 or CXCR2) to activate and promote chemotaxis of neutrophils (Holmes et al., 1991;

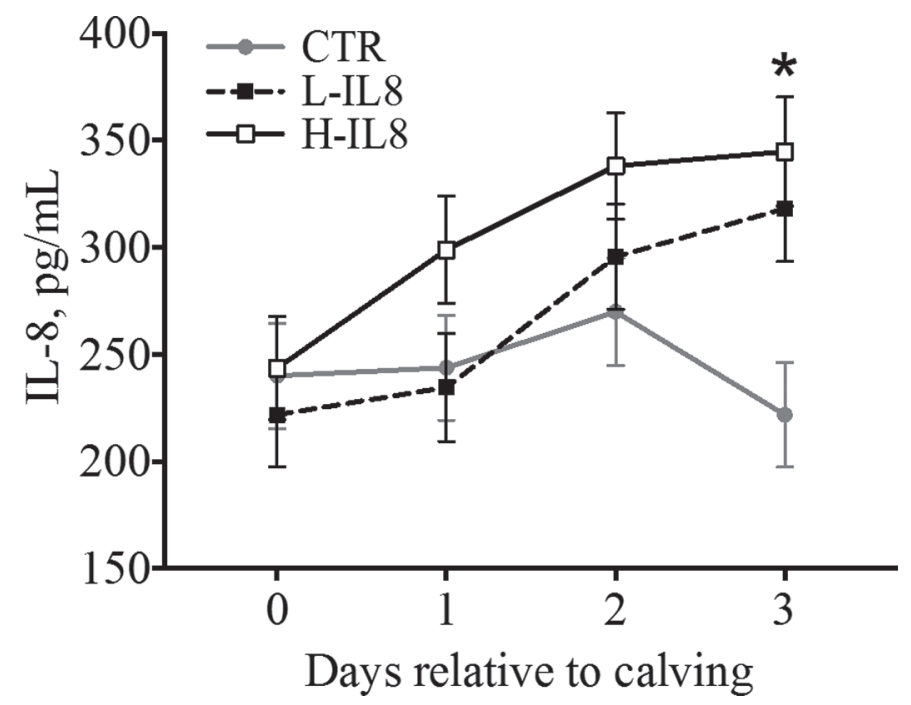

Figure 2. Interleukin-8 plasma concentrations of cows treated with different recombinant bovine interleukin- 8 (rbIL- 8 ) doses and controls from study 1 . Postpartum cows $(\mathrm{n}=213)$ were randomly allocated into 1 of 3 intrauterine treatment groups: control (CTR; $250 \mathrm{~mL}$ of saline solution), low dose (L-IL8; $11.25 \mu \mathrm{g}$ of rbIL-8 diluted in $250 \mathrm{~mL}$ of saline solution), and high dose (H-IL8, 1,125 $\mu \mathrm{g}$ of rbIL-8 diluted in $250 \mathrm{~mL}$ of saline solution). Blood samples were harvested from a subset of cows (20/treatment group). Results are presented at LSM \pm SEM. $* P \leq 0.05$. 

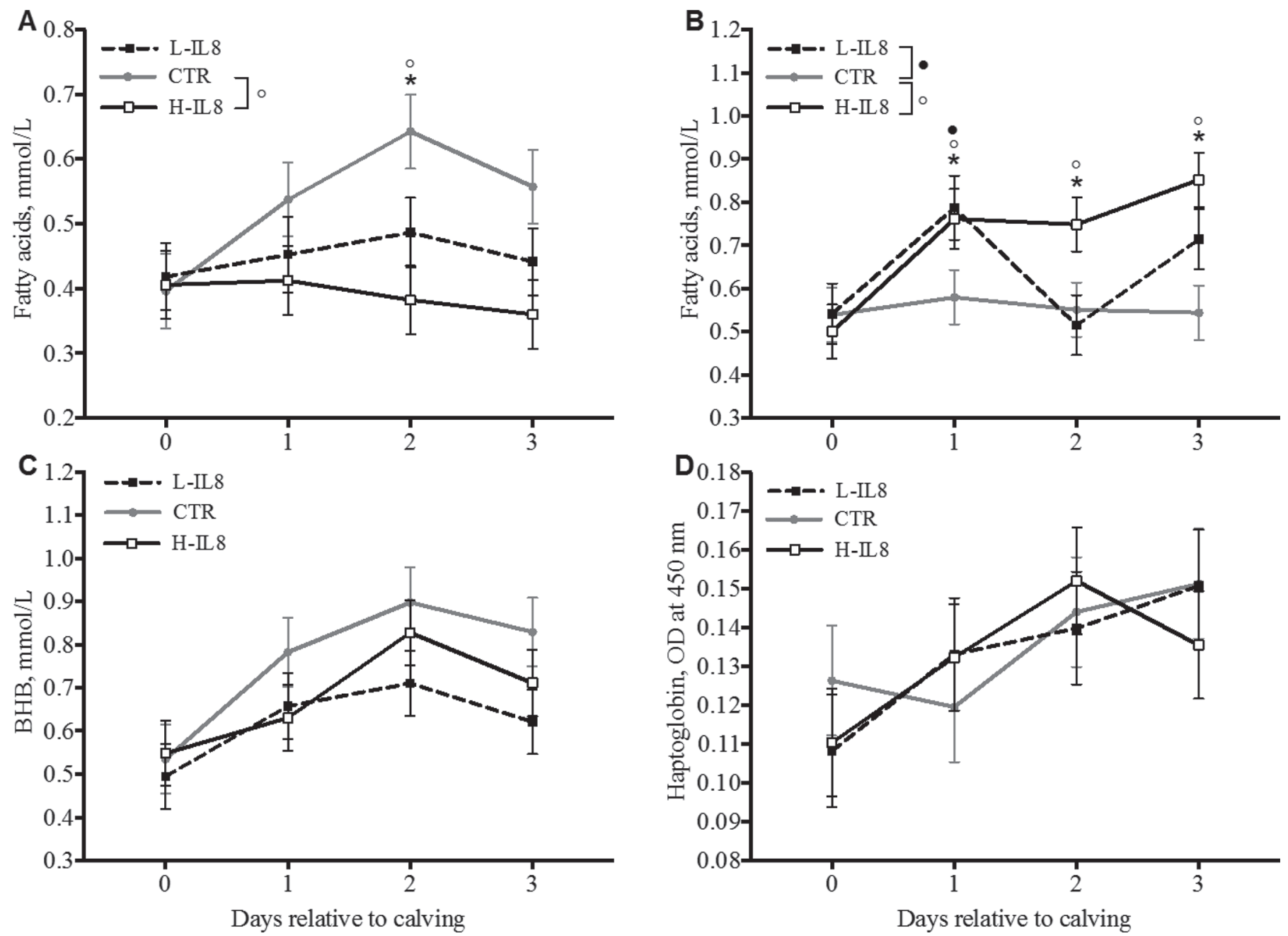

Figure 3. Fatty acid serum levels of primiparous (A) and multiparous (B) cows, and BHB (C) and haptoglobin (D) serum levels of cows treated with recombinant bovine interleukin-8 (rbIL-8) and controls from study 1 . Postpartum cows $(\mathrm{n}=213)$ were randomly allocated into 1 of 3 intrauterine treatment groups: control (CTR; $250 \mathrm{~mL}$ of saline solution), low dose (L-IL8; $11.25 \mu \mathrm{g}$ of rbIL-8 diluted in $250 \mathrm{~mL}$ of saline solution), and high dose (H-IL8, 1,125 $\mathrm{g}$ of rbIL-8 diluted in $250 \mathrm{~mL}$ of saline solution). Blood samples were harvested from a subset of cows (20/treatment group). Results are presented at LSM \pm SEM. $* P \leq 0.05$. OD $=$ optical density.

Mitchell et al., 2003). In the last decades the list of functions attributed to IL-8 is expanding. For instance, due to the presence of a sequence motif (Glu-Leu-Arg), named ELR, IL-8 belongs to a subset of chemokines associated with angiogenic properties (Onuffer and Horuk, 2002). Moreover, recent experiments have demonstrated that IL-8 exerts mitogenic and antiapoptotic effects (Colletti et al., 1998; Hogaboam et al., 1999; Osawa et al., 2002).

Lipolysis is dramatically increased during the postpartum period because of increased responsiveness of adipose tissue to catecholamines, low blood insulin concentration, and decreased peripheral insulin sensitivity (McNamara and Hillers, 1986; De Koster and Opsomer, 2013; Saremi et al., 2014). All these metabolic changes are part of the homeorhetic shifts that postpartum cows experience to support lactation nutrient demands (Bell and Bauman, 1997). Upon binding to its receptor, insulin triggers a cascade of events that involve several proteins, such as insulin receptor substrates, phosphatidylinositol-3-kinase, and 3-phospohoinositide-dependent protein kinase 1, which leads to the activation of AKT protein kinase (Chang et al., 2004). Activation of AKT results in GLUT-4 translocation and glucose uptake (Kohn et al., 1996). Interleukin- 8 is a pro-inflammatory cytokine associated with development of insulin resistance (Fujishiro et al., 2003; Kobashi et al., 2009; Hardy et al., 2011). Kobashi et al. (2009) demonstrated in vitro that IL-8 can promote insulin resistance via the inhibition of AKT activation through MAPK/ERK pathway. In addition, stimulation of toll-like receptors of adipocytes with 

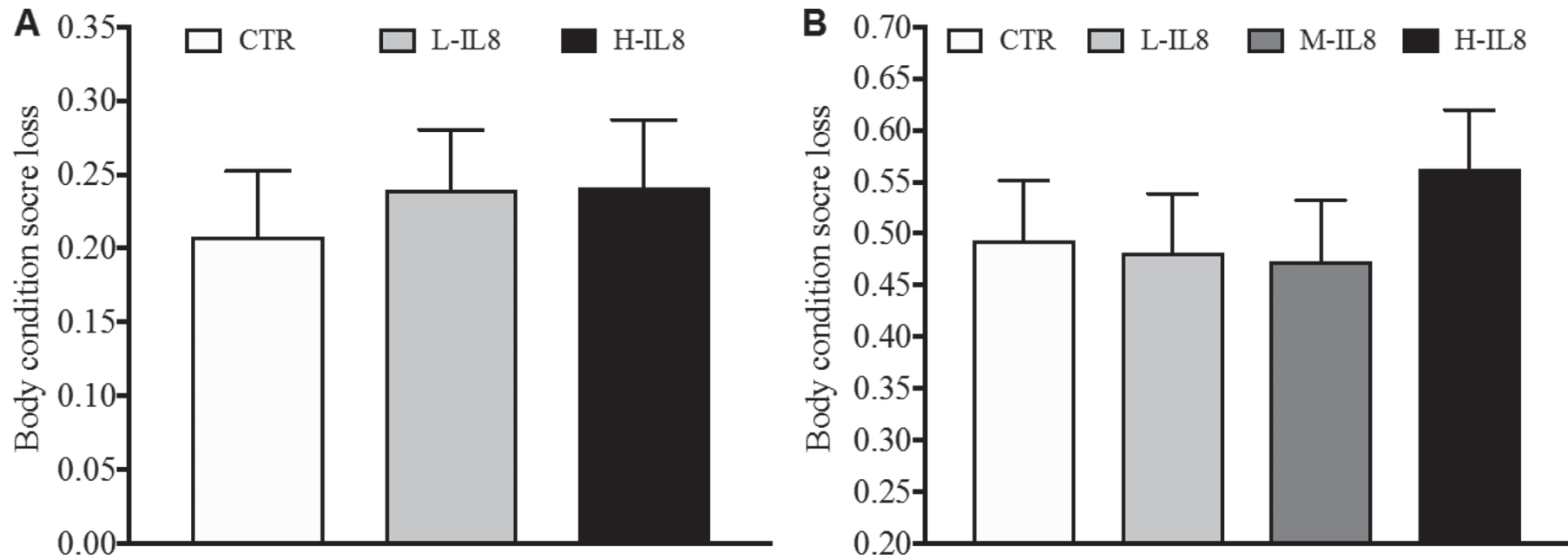

Figure 4. Body condition score loss from day of enrollment (day of parturition) until 35 DIM of cows treated with different doses of recombinant bovine interleukin-8 (rbIL-8) and controls from studies 1 (A) and 2 (B). For study 1, 213 cows were randomly allocated into 1 of 3 intrauterine treatment groups: control (CTR; $250 \mathrm{~mL}$ of saline solution), low dose (L-IL8; $11.25 \mu \mathrm{g}$ of rbIL-8 diluted in $250 \mathrm{~mL}$ of saline solution), and high dose (H-IL8, $1,125 \mu \mathrm{g}$ of rbIL- 8 diluted in $250 \mathrm{~mL}$ of saline solution). For study 2, 164 cows were randomly allocated into 1 of 4 treatment groups: control (CTR, $250 \mathrm{~mL}$ of saline solution), low dose (L-IL8, $0.14 \mu \mathrm{g}$ of rbIL-8), medium dose (M-IL8, $14 \mu \mathrm{g}$ of rbIL-8), and high dose (H-IL8, 1,400 $\mu \mathrm{g}$ of rbIL-8). Results are presented at LSM \pm SEM.

bacterial particles induced the expression of IL-8, impaired insulin-mediated glucose transport, stimulated lipolysis, and led to insulin resistance (Franchini et al., 2010), which are all metabolic changes that ensure glucose availability to support the immune response to lipopolysaccharides. Therefore, it is possible that the dramatic increases in milk production herein observed because of rbIL-8 use is a consequence of increased insulin resistance, which could be supporting nutrient partitioning toward the mammary gland.

The increase in milk production observed in dairy cows treated with exogenous bST occurs through complex and coordinated physiological processes that involve multiple tissues, metabolites, and hormones.
One of the major effects of bST is to promote insulin resistance (Bauman and Vernon, 1993). Furthermore, a recent study revealed that feeding mid-lactation cows with palmitic acid promotes insulin resistance through sphingolipid ceramide-dependent mechanisms (Mathews et al., 2016). In that study, treated cows showed increased milk yield even after the palmitic acid was removed from the diet (Mathews et al., 2016). Therefore, facilitating glucose partitioning by decreasing insulin action seems to be a key strategy to enhance milk production.

Growth hormone (GH) stimulates the liver to produce IGF-I. However, during the early lactation, high blood GH concentration cannot restore blood IGF-1

Table 3. Effect of different recombinant bovine interleukin-8 (rbIL-8) doses on production parameters of cows from studies 1 and 2 during the first 6 mo after calving

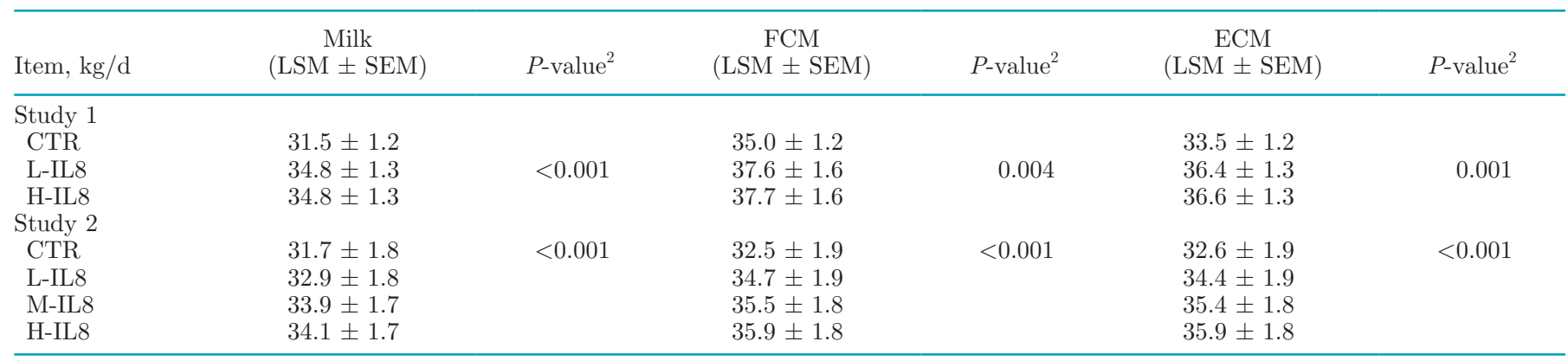

${ }^{1}$ Study $1:$ CTR $=250 \mathrm{~mL}$ of saline solution, $\mathrm{n}=67 ; \mathrm{L}-\mathrm{IL} 8=11.25 \mu \mathrm{g}$ of rbIL-8 diluted in $250 \mathrm{~mL}$ of saline solution, $\mathrm{n}=80 ; \mathrm{H}-\mathrm{IL} 8=1,125 \mu \mathrm{g}$ of rbIL-8 diluted in $250 \mathrm{~mL}$ of saline solution, $\mathrm{n}=66$. Study 2 : CTR $=250 \mathrm{~mL}$ of saline solution, $\mathrm{n}=41 ; \mathrm{L}-\mathrm{IL} 8=0.14 \mu \mathrm{g}$ of rbIL-8 diluted in $250 \mathrm{~mL}$ of saline solution, $\mathrm{n}=41$; M-IL8 $=14 \mu \mathrm{g}$ of rbIL-8 diluted in $250 \mathrm{~mL}$ of saline solution, $\mathrm{n}=41$; H-IL8 $=1,400 \mu \mathrm{g}$ of rbIL-8 diluted in $250 \mathrm{~mL}$ of saline solution, $\mathrm{n}=41$

${ }^{2} P$-values indicate overall treatment effects. 

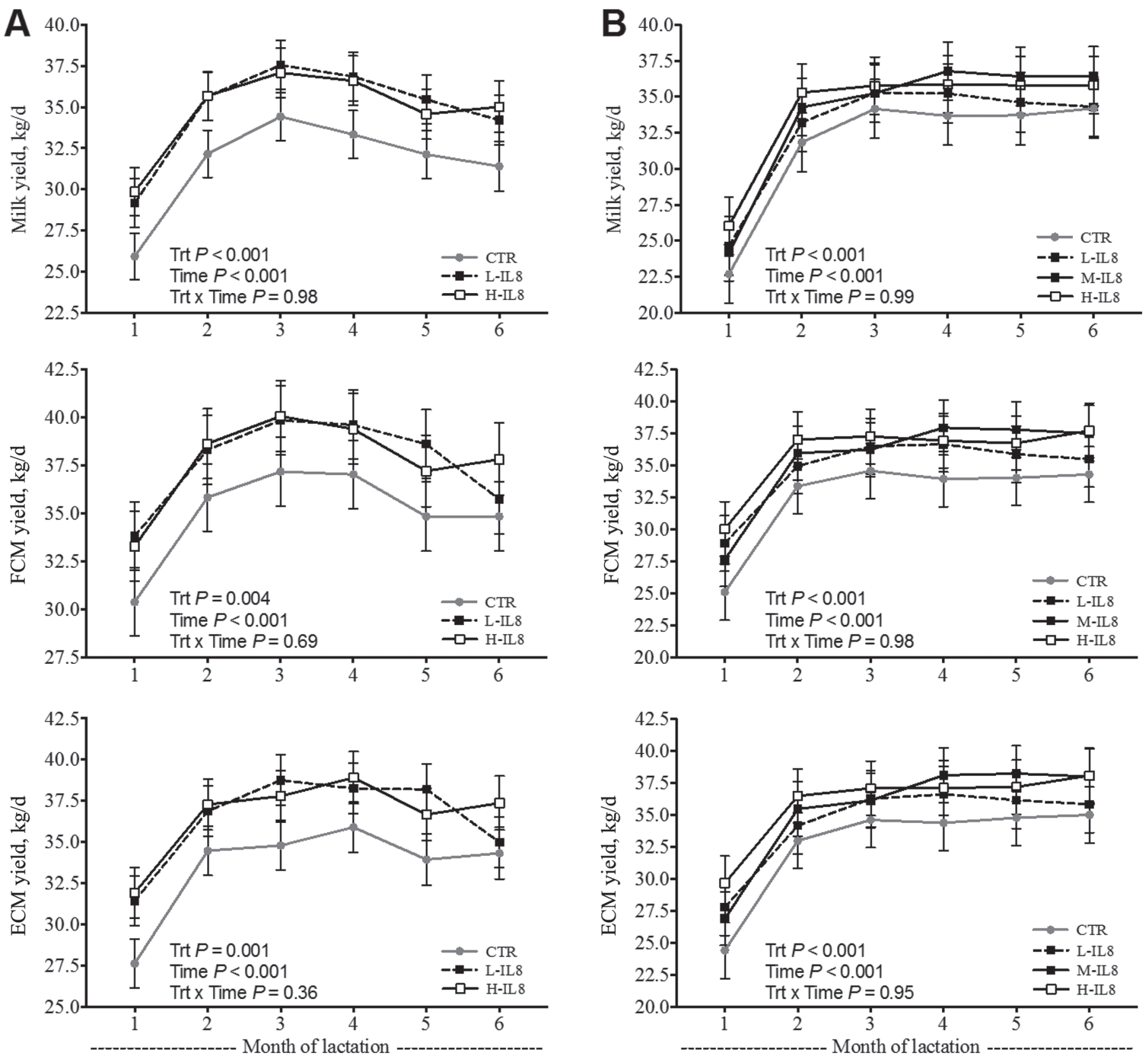

Figure 5. Monthly milk yields $(\mathrm{kg} / \mathrm{d}), 3.5 \% \mathrm{FCM}$ yields $(\mathrm{kg} / \mathrm{d})$, and ECM yields $(\mathrm{kg} / \mathrm{d})$ after parturition of cows treated with different doses of recombinant bovine interleukin-8 (rbIL-8) and controls from studies 1 (A) and 2 (B). For study 1, 213 cows were randomly allocated into 1 of 3 intrauterine treatment groups: control (CTR; $250 \mathrm{~mL}$ of saline solution), low dose (L-IL8; $11.25 \mu \mathrm{g}$ of rbIL-8 diluted in $250 \mathrm{~mL}$ of saline solution), and high dose (H-IL8, 1,125 $\mu \mathrm{g}$ of rbIL-8 diluted in $250 \mathrm{~mL}$ of saline solution). For study 2 , 164 cows were randomly allocated into 1 of 4 treatment groups: control (CTR, $250 \mathrm{~mL}$ of saline solution), low dose (L-IL8, $0.14 \mu \mathrm{g}$ of rbIL-8), medium dose (M-IL8, $14 \mu \mathrm{g}$ of rbIL-8), and high dose (H-IL8, 1,400 $\mu \mathrm{g}$ of rbIL-8). The $P$-values for the fixed effect of treatment (Trt), time, and the interaction term treatment by time are included in each graph. Results are presented at LSM \pm SEM.

levels due to the reduced expression and abundance of liver-specific GH receptor (Rhoads et al., 2007). A negative feedback control of GH actions occurs via the increased concentration of IGF-1. It has been shown that GH signaling could be altered via the production of suppressors of cytokine signaling (SOCS) proteins
(Rico-Bautista et al., 2006). Interleukin-8 promotes the production of SOCS (Stevenson et al., 2004). Thus, it is possible that IL-8 inhibited the GH signaling via SOCS production, which will result in lower production of IGF-1, thus exacerbating the un-coupling of the GH/ IGF-1 axis that characterizes a postpartum dairy cow 
during the early lactation. Further studies evaluating plasma IGF-1 and GH concentrations in Holstein cows treated with rbIL-8 during the early lactation are necessary to address this hypothesis.

Optimal hepatic function is critical for proper transition into lactation. The hepatic release of glucose increases from 1.4 , to 2.7 , and to $3.5 \mathrm{~kg} / \mathrm{d}$ between $-9,11$, and 33 d relative to parturition due to greater uptake of substrates and expression of gluconeogenesis rate-limiting enzymes (Greenfield et al., 2000; Reynolds et al., 2003; Selim et al., 2014). Moreover, the liver extracts about $20 \%$ of the circulating fatty acids and is the major organ involved with lipid metabolism during the transition period (Reynolds et al., 2003). Within the hepatocytes, fatty acids can be esterified into triglycerides, completely oxidized to generate ATP, or partially oxidized into ketone bodies that can be used as an energy source by other tissues and as a substrate for milk fat synthesis.

In the present study, intrauterine rbIL- 8 treatment reduced the incidence of postpartum HYK and CK, both only numerically. Studies with human and rat hepatocytes showed that recombinant IL-8 reduced apoptosis and stimulated cell proliferation in vitro (Colletti et al., 1998; Osawa et al., 2002). For instance, antibody neutralization of CXC chemokines impaired liver regeneration in rats subjected to $70 \%$ hepatectomy (Colletti et al., 1998). Moreover, mice treated with recombinant IL-8 and concanavalin A-induced liver damage resulted in lower transaminase activities (AST and ALT) and significantly reduced liver damage (Osawa et al., 2002). It is possible that the treatment with rbIL- 8 in our study reduced hepatocyte apoptosis and increased cell proliferation, thus increasing the number of cells available to process nutrients and metabolites. As a result, the liver would have been able to oxidize a larger amount of fatty acids before the tricarboxylic acid cycle was inhibited due to excess ATP/NADH and depression of appetite associated with hepatic oxidation; the upshot would be reduced BHB production and reduced lipid accumulation within hepatocytes. However, further investigation is needed to address this hypothesis. Further studies with a larger sample size are needed to evaluate whether differences in HYK and CK during the early postpartum should be expected with the use of rbIL-8.

Moreover, the observed positive effect on milk yield was not associated with increased BCS loss. Therefore, rbIL- 8 treatment might stimulate appetite and increase feed intake, and therefore it would not significantly affect BCS and would reduce the incidence of HYK and CK. More studies are needed to evaluate the effect of rbIL-8 treatment during the early lactation in Holstein cows on DMI.
The activation of NF- $\kappa \mathrm{B}$ during mammary gland development is critical for mammary cell differentiation (Brantley et al., 2001; Cao et al., 2001). Prolactin and progesterone are the primary hormones necessary to ensure proper mammary gland development during pregnancy. Interestingly, it has been demonstrated that both hormones induced the expression of receptor activator of NF- $\kappa \mathrm{B}$ ligand (RANKL), which is essential to activate NF- $\kappa \mathrm{B}$ and upregulate cycling D1 (Srivastava et al., 2003). Interleukin-8 is also known as an activator of RANKL (Bendre et al., 2003). Therefore, it is also possible that the observed effect of IL- 8 administration on milk yield might be, at least in part, due its potential direct effects on mammary gland tissue development. Furthermore, IL-8 also promotes angiogenesis through the stimulation of a potent vasculogenic and angiogenic factor, named vascular endothelial growth factor (VEGF), by the activation of different signaling pathways (Strieter et al., 1995; Martin et al., 2009; Hou et al., 2014). Along this line, we speculate that IL-8 might also increase mammary gland and liver blood flow, which would result in an increased oxygen and nutrient supply and ultimately promote tissue proliferation in those organs.

Taken together, considering the effects of rbIL-8 treatment that we observed on circulating metabolites and on milk production, and the evidence that IL-8 might induce insulin resistance (Kobashi et al., 2009), increase SOCS proteins (Stevenson et al., 2004), promote angiogenesis (Martin et al., 2009), and reduce apoptosis and stimulate cell proliferation (Colletti et al., 1998; Osawa et al., 2002), we hypothesize that a single administration of rbIL-8 at the day of calving might involve one or several biological processes: increase insulin resistance in peripheral tissues, favor the un-coupling of the GH/IGF-1 axis, increase mammary cell proliferation, increase DMI, and enhance hepatic function during lactation, thus improving metabolic health and milk yield in Holstein cows. However, the precise mechanism underlying the role of rbIL- 8 on milk yield in dairy cows, particularly in controlling homeorhesis, remains to be studied.

Uterine diseases are highly correlated with bacterial contamination and immune suppression (Dubuc et al., 2010; Bicalho et al., 2012). Thus, recruitment of neutrophils to the uterine lumen is a key factor for early clearance of bacterial contamination (Kimura et al., 2002; Hammon et al., 2006). Herein, the intrauterine administration of rbIL-8 significantly reduced the incidence of puerperal metritis in multiparous cows. Although, in the present study, we did not evaluate the proportion of neutrophils in the reproductive tract, we have previously demonstrated that Holstein heifers and nonpregnant lactating cows that received vaginal 
and intrauterine administration of rbIL-8 had a higher proportion of neutrophils in their reproductive tract when compared with controls (Bicalho et al., 2019). Additionally, our previous work also demonstrated its chemoattractant properties in vitro (Bicalho et al., 2019). Thus, we suggest that intrauterine administration of rbIL-8 within $12 \mathrm{~h}$ of parturition increases neutrophil migration and activation to the reproductive tract, which would result in early clearance of bacterial contamination.

We did not observe an effect of treatment on puerperal metritis for primiparous cows. Antibodies are the major and most important opsonin molecules of the adaptive immune system (Hiemstra and Daha, 1998). As neutrophils encounter a bacterium, opsonins neutralize the bacterium electrostatic charge by coating them with positively charged molecules, facilitating the interaction of the negatively charged neutrophils with the opsonin-coated bacteria. More importantly, antibodies are required to recognize specific bacteria to signal neutrophils to initiate phagocytosis (Hiemstra and Daha, 1998; Rosales et al., 2016). Because primiparous animals have never been exposed to postpartum uterine disease, they are very susceptible to reproductive tract infections in the early postpartum period. It is possible that the lack of effect of rbIL- 8 treatment on puerperal metritis in primiparous cows was due to absence of specific antibodies against pathogens associated with puerperal metritis. Another possible explanation is that the dose used in the present study was too high for primiparous cows. Although the intrauterine administration of rbIL- 8 did not significantly increase the incidence of puerperal metritis in primiparous cows, we observed a numerical increase in a dose-dependent manner. Therefore, is possible that an excessive migration and activation of neutrophils triggered by rbIL-8 treatment could cause a more robust inflammatory response and thus more cows exhibiting altered uterine discharge and systemic clinical signs. More studies are needed to evaluate these hypotheses.

Moreover, it has been hypothesized that RFM is caused by an impaired immune function during the peripartum period, with a special emphasis on neutrophil function and migration. Thus, the failure of placental detachment seems to be, at least in part, due to a reduced ability of neutrophils to digest the cotyledon-caruncle attachment after parturition. Interleukin- 8 plays a key role in the pathogenesis of RFM. It was previously demonstrated that cows that developed RFM had impaired neutrophil function and lower plasma IL-8 concentrations before and after calving compared with cows that did not develop RFM (Kimura et al., 2002). In addition, IL-8 was reported to induce neutrophil collagenase and elastase expression, which are enzymatic activities involved in fetal membrane detachment and cervical dilation (Kanayama et al., 1988; Rath et al., 1998). This study was not powered to compare the effect of treatment on incidence of RFM. Therefore, the results presented here on RFM are inconclusive. In the present study, we did not have the power to compare the effect of treatment on incidence of uterine diseases of cows treated early or those treated closer to $12 \mathrm{~h}$ after calving. It is possible that rbIL- 8 could have a beneficial effect on RFM if it was applied earlier, either before parturition or immediately after delivery of the calf. This hypothesis remains to be evaluated.

Although our study evaluated the effect of rbIL-8 treatment in 2 separate randomized clinical trials, the external generalization of the results must be made cautiously because it was limited to a single dairy farm.

\section{CONCLUSIONS}

In summary, intrauterine rbIL-8 treatment reduced the incidence of puerperal metritis in multiparous cows. More research with a larger sample size is needed to evaluate immediate administration of rbIL- 8 after delivery of the calf on RFM. More importantly, treatment with intrauterine rbIL-8 within $12 \mathrm{~h}$ after calving increased milk, FCM, and ECM yields in the long term. Further research on lactating cows is needed to evaluate rbIL-8 effects on liver function, DMI, cell proliferation and apoptosis in the liver and mammary gland, metabolic parameters, and its potential effect on the homeorhetic shifts that occur after calving to support lactation.

\section{ACKNOWLEDGMENTS}

This work was partially supported by Zoetis Animal Health (Kalamazoo) and by Agriculture and Food Research Initiative Competitive Grant No 2017-6701526541 from the United States Department of Agriculture National Institute of Food and Agriculture.

\section{REFERENCES}

Bauman, D. E., and R. G. Vernon. 1993. Effects of exogenous bovine somatotropin on lactation. Annu. Rev. Nutr. 13:437-461.

Bell, A. W., and D. E. Bauman. 1997. Adaptations of glucose metabolism during pregnancy and lactation. J. Mammary Gland Biol. Neoplasia 2:265-278.

Bendre, M. S., D. C. Montague, T. Peery, N. S. Akel, D. Gaddy, and L. J. Suva. 2003. Interleukin-8 stimulation of osteoclastogenesis and bone resorption is a mechanism for the increased osteolysis of metastatic bone disease. Bone 33:28-37.

Bicalho, M. L. S., F. S. Lima, E. K. Ganda, C. Foditsch, E. B. Meira Jr., V. S. Machado, A. G. Teixeira, G. Oikonomou, R. O. Gilbert, and R. C. Bicalho. 2014. Effect of trace mineral supplementation on selected minerals, energy metabolites, oxidative stress, and im- 
mune parameters and its association with uterine diseases in dairy cattle. J. Dairy Sci. 97:4281-4295.

Bicalho, M. L. S., V. S. Machado, G. Oikonomou, R. O. Gilbert, and R. C. Bicalho. 2012. Association between virulence factors of Escherichia coli, Fusobacterium necrophorum, and Arcanobacterium pyogenes and uterine diseases of dairy cows. Vet. Microbiol. 157:125-131.

Bicalho, M. L. S., M. Zinicola, V. S. Machado, F. S. Lima, A. G. V. Teixeira, C. Narbus, M. R. Xavier, H. Higgins, and R. C. Bicalho. 2019. Effects of recombinant bovine interleukin-8 (rbIL-8) treatment on health, metabolism, and lactation performance in Holstein cattle I: Production and functional characterization of rbIL-8 in vitro and in vivo. 102:10304-10315. https://doi.org/10 .3168/jds.2019-16334.

Brantley, D. M., C. L. Chen, R. S. Muraoka, P. B. Bushdid, J. L. Bradberry, F. Kittrell, D. Medina, L. M. Matrisian, L. D. Kerr, and F. E. Yull. 2001. Nuclear factor-kappaB (NF-kappaB) regulates proliferation and branching in mouse mammary epithelium. Mol. Biol. Cell 12:1445-1455.

Cao, Y., G. Bonizzi, T. N. Seagroves, F. R. Greten, R. Johnson, E. V. Schmidt, and M. Karin. 2001. IKKalpha provides an essential link between RANK signaling and cyclin D1 expression during mammary gland development. Cell 107:763-775.

Chang, L., S. H. Chiang, and A. R. Saltiel. 2004. Insulin signaling and the regulation of glucose transport. Mol. Med. 10:65-71.

Colletti, L. M., M. Green, M. D. Burdick, S. L. Kunkel, and R. M. Strieter. 1998. Proliferative effects of CXC chemokines in rat hepatocytes in vitro and in vivo. Shock 10:248-257.

De Koster, J. D., and G. Opsomer. 2013. Insulin resistance in dairy cows. Vet. Clin. North Am. Food Anim. Pract. 29:299-322.

Drackley, J. K. 1999. ADSA Foundation Scholar Award. Biology of dairy cows during the transition period: the final frontier? J. Dairy Sci. 82:2259-2273.

Dubuc, J., T. F. Duffield, K. E. Leslie, J. S. Walton, and S. J. LeBlanc. 2010. Risk factors for postpartum uterine diseases in dairy cows. J. Dairy Sci. 93:5764-5771.

Edmonson, A. J., I. J. Lean, L. D. Weaver, T. Farver, and G. Webster. 1989. A body condition scoring chart for Holstein dairy cows. J. Dairy Sci. 72:68-78.

Franchini, M., E. Monnais, D. Seboek, T. Radimerski, E. Zini, K. Kaufmann, T. Lutz, C. Reusch, M. Ackermann, B. Muller, and P. Linscheid. 2010. Insulin resistance and increased lipolysis in bone marrow derived adipocytes stimulated with agonists of Toll-like receptors. Horm. Metab. Res. 42:703-709.

Fricke, P. M., D. Z. Caraviello, K. A. Weigel, and M. L. Welle. 2003. Fertility of dairy cows after resynchronization of ovulation at three intervals following first timed insemination. J. Dairy Sci. 86:39413950.

Fujishiro, M., Y. Gotoh, H. Katagiri, H. Sakoda, T. Ogihara, M. Anai, Y. Onishi, H. Ono, M. Abe, N. Shojima, Y. Fukushima, M. Kikuchi, Y. Oka, and T. Asano. 2003. Three mitogen-activated protein kinases inhibit insulin signaling by different mechanisms in 3T3L1 adipocytes. Mol. Endocrinol. 17:487-497.

Galvao, K. N., M. J. B. F. Flaminio, S. B. Brittin, R. Sper, M. Fraga, L. Caixeta, A. Ricci, C. L. Guard, W. R. Butler, and R. O. Gilbert. 2010. Association between uterine disease and indicators of neutrophil and systemic energy status in lactating Holstein cows. J. Dairy Sci. 93:2926-2937.

Gilbert, R. O., S. T. Shin, C. L. Guard, H. N. Erb, and M. Frajblat. 2005. Prevalence of endometritis and its effects on reproductive performance of dairy cows. Theriogenology 64:1879-1888.

Goff, J. P., and R. L. Horst. 1997. Physiological changes at parturition and their relationship to metabolic disorders. J. Dairy Sci. 80:1260-1268.

Greenfield, R. B., M. J. Cecava, and S. S. Donkin. 2000. Changes in mRNA expression for gluconeogenic enzymes in liver of dairy cattle during the transition to lactation. J. Dairy Sci. 83:1228-1236.

Hammon, D. S., I. M. Evjen, T. R. Dhiman, J. P. Goff, and J. L. Walters. 2006. Neutrophil function and energy status in Holstein cows with uterine health disorders. Vet. Immunol. Immunopathol. 113:21-29
Han, I. K., and I. H. Kim. 2005. Risk factors for retained placenta and the effect of retained placenta on the occurrence of postpartum diseases and subsequent reproductive performance in dairy cows. J. Vet. Sci. 6:53-59.

Hardy, O. T., R. A. Perugini, S. M. Nicoloro, K. Gallagher-Dorval, V. Puri, J. Straubhaar, and M. P. Czech. 2011. Body mass indexindependent inflammation in omental adipose tissue associated with insulin resistance in morbid obesity. Surg. Obes. Relat. Dis. 7:60-67.

Hiemstra, P. S., and M. R. D. Daha. 1998. Encyclopedia of Immunology (Second Edition). P. J. Delves, ed. Elsevier 1998:1885-1888. https://doi.org/10.1006/rwei.1999.0475.

Hogaboam, C. M., C. L. Bone-Larson, M. L. Steinhauser, N. W. Lukacs, L. M. Colletti, K. J. Simpson, R. M. Strieter, and S. L. Kunkel. 1999. Novel CXCR2-dependent liver regenerative qualities of ELR-containing CXC chemokines. FASEB J. 13:1565-1574.

Holmes, W. E., J. Lee, W. J. Kuang, G. C. Rice, and W. I. Wood. 1991. Structure and functional expression of a human interleukin- 8 receptor. Science 253:1278-1280.

Hou, Y., C. H. Ryu, J. A. Jun, S. M. Kim, C. H. Jeong, and S. S. Jeun. 2014. IL-8 enhances the angiogenic potential of human bone marrow mesenchymal stem cells by increasing vascular endothelial growth factor. Cell Biol. Int. 38:1050-1059.

Hussain, A. M. 1989. Bovine uterine defense-mechanisms - A review. J. Vet. Med. B Infect. Dis. Vet. Public Health 36:641-651.

Kanayama, N., T. Terao, and K. Horiuchi. 1988. The role of human neutrophil elastase in the premature rupture of membranes. Asia Oceania J. Obstet. Gynaecol. 14:389-397.

Kehrli, M. E., and J. P. Goff. 1989. Periparturient hypocalcemia in cows - Effects on peripheral blood neutrophil and lymphocyte function. J. Dairy Sci. 72:1188-1196.

Kimura, K., J. P. Goff, M. E. Kehrli, and T. A. Reinhardt. 2002. Decreased neutrophil function as a cause of retained placenta in dairy cattle. J. Dairy Sci. 85:544-550.

Kobashi, C., S. Asamizu, M. Ishiki, M. Iwata, I. Usui, K. Yamazaki, K. Tobe, M. Kobayashi, and M. Urakaze. 2009. Inhibitory effect of IL-8 on insulin action in human adipocytes via MAP kinase pathway. J. Inflamm. (Lond.) 6:25.

Kohn, A. D., S. A. Summers, M. J. Birnbaum, and R. A. Roth. 1996 Expression of a constitutively active Akt Ser/Thr kinase in 3T3L1 adipocytes stimulates glucose uptake and glucose transporter 4 translocation. J. Biol. Chem. 271:31372-31378.

Martin, D., R. Galisteo, and J. S. Gutkind. 2009. CXCL8/IL8 stimulates vascular endothelial growth factor (VEGF) expression and the autocrine activation of VEGFR2 in endothelial cells by activating NFkappaB through the CBM (Carma3/Bcl10/Malt1) complex. J. Biol. Chem. 284:6038-6042.

Mathews, A. T., J. E. Rico, N. T. Sprenkle, A. L. Lock, and J. W. McFadden. 2016. Increasing palmitic acid intake enhances milk production and prevents glucose-stimulated fatty acid disappearance without modifying systemic glucose tolerance in mid-lactation dairy cows. J. Dairy Sci. 99:8802-8816.

McNamara, J. P., and J. K. Hillers. 1986. Adaptations in lipid metabolism of bovine adipose tissue in lactogenesis and lactation. J. Lipid Res. 27:150-157.

Mitchell, G. B., B. N. Albright, and J. L. Caswell. 2003. Effect of interleukin-8 and granulocyte colony-stimulating factor on priming and activation of bovine neutrophils. Infect. Immun. 71:1643-1649.

Moreira, F., C. Orlandi, C. A. Risco, R. Mattos, F. Lopes, and W. W. Thatcher. 2001. Effects of presynchronization and bovine somatotropin on pregnancy rates to a timed artificial insemination protocol in lactating dairy cows. J. Dairy Sci. 84:1646-1659.

NRC. 2001. Nutrient Requirements of Dairy Cattle. 7th rev. ed. National Academy Press, Washington, DC

Onuffer, J. J., and R. Horuk. 2002. Chemokines, chemokine receptors and small-molecule antagonists: Recent developments. Trends Pharmacol. Sci. 23:459-467.

Osawa, Y., M. Nagaki, Y. Banno, D. A. Brenner, T. Asano, Y. Nozawa, H. Moriwaki, and S. Nakashima. 2002. Tumor necrosis factor alpha-induced interleukin- 8 production via NF-B and phosphati- 
dylinositol 3-kinase/Akt pathways inhibits cell apoptosis in human hepatocytes. Infect. Immun. 70:6294-6301.

Overton, M., and J. Fetrow. 2008. Economics of postpartum uterine health. Pages 39-43 in Proc. Dairy Cattle Reprod. Council Conv., Omaha, NE. Dairy Cattle Reproductive Council, Hartland, WI.

Pursley, J. R., M. O. Mee, and M. C. Wiltbank. 1995. Synchronization of ovulation in dairy cows using PGF2alpha and GnRH. Theriogenology 44:915-923.

Rath, W., M. Winkler, and B. Kemp. 1998. The importance of extracellular matrix in the induction of preterm delivery. J. Perinat. Med. 26:437-441.

Reynolds, C. K., P. C. Aikman, B. Lupoli, D. J. Humphries, and D. E. Beever. 2003. Splanchnic metabolism of dairy cows during the transition from late gestation through early lactation. J. Dairy Sci. 86:1201-1217.

Rhoads, R. P., J. W. Kim, M. E. Van Amburgh, R. A. Ehrhardt, S. J. Frank, and Y. R. Boisclair. 2007. Effect of nutrition on the GH responsiveness of liver and adipose tissue in dairy cows. J. Endocrinol. 195:49-58.

Rico-Bautista, E., A. Flores-Morales, and L. Fernandez-Perez. 2006. Suppressor of cytokine signaling (SOCS) 2, a protein with multiple functions. Cytokine Growth Factor Rev. 17:431-439.

Rosales, C., N. Demaurex, C. A. Lowell, and E. Uribe-Querol. 2016. Neutrophils: Their role in innate and adaptive immunity. J. Immunol. Res. 2016:1469780.

Saremi, B., S. Winand, P. Friedrichs, A. Kinoshita, J. Rehage, S. Danicke, S. Haussler, G. Breves, M. Mielenz, and H. Sauerwein. 2014. Longitudinal profiling of the tissue-specific expression of genes related with insulin sensitivity in dairy cows during lactation focusing on different fat depots. PLoS One 9:e86211.
Selim, S., S. Salin, J. Taponen, A. Vanhatalo, T. Kokkonen, and K. T. Elo. 2014. Prepartal dietary energy alters transcriptional adaptations of the liver and subcutaneous adipose tissue of dairy cows during the transition period. Physiol. Genomics 46:328-337.

Sheldon, I. M., G. S. Lewis, S. LeBlanc, and R. O. Gilbert. 2006 Defining postpartum uterine disease in cattle. Theriogenology 65:1516-1530.

Shuster, D. E., E. K. Lee, and M. E. Kehrli. 1996. Bacterial growth, inflammatory cytokine production, and neutrophil recruitment during coliform mastitis in cows within ten days after calving, compared with cows at midlactation. Am. J. Vet. Res. 57:1569-1575.

Srivastava, S., M. Matsuda, Z. Hou, J. P. Bailey, R. Kitazawa, M. P. Herbst, and N. D. Horseman. 2003. Receptor activator of NF-kap$\mathrm{paB}$ ligand induction via Jak2 and Stat5a in mammary epithelial cells. J. Biol. Chem. 278:46171-46178.

Stevenson, N. J., S. Haan, A. E. McClurg, M. J. McGrattan, M. A. Armstrong, P. C. Heinrich, and J. A. Johnston. 2004. The chemoattractants, IL-8 and formyl-methionyl-leucyl-phenylalanine, regulate granulocyte colony-stimulating factor signaling by inducing suppressor of cytokine signaling-1 expression. J. Immunol. 173:3243-3249

Strieter, R. M., P. J. Polverini, S. L. Kunkel, D. A. Arenberg, M. D Burdick, J. Kasper, J. Dzuiba, J. Van Damme, A. Walz, D. Marriott, S.-Y. Chan, S. Roczniak, and A. B. Shanafelt. 1995. The functional role of the ELR motif in CXC chemokine-mediated angiogenesis. J. Biol. Chem. 270:27348-27357.

Williamson, D. H., and J. Mellanby. 1974. D-(-)-3-hydroxybutyrate. Pages 1836-1839 in Methods of Enzymatic Analysis. H. U. Bergmeyer, ed. Academic Press, New York, NY. 